International Review of Research in Open and Distributed Learning Volume 16, Number 2

April - 2015

\title{
Linking Learning Styles and Learning on Mobile Facebook
}

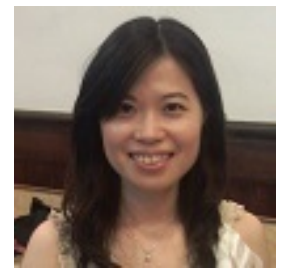

Yu-ching Chen

Chinese Culture University, Taiwan

\begin{abstract}
With continued development of related technologies, Web 2.0 has become an important site of learning innovation. In particular, social networking sites such as Facebook, which have become popular, have the potential to function as an educational tool enabling peer feedback, interaction, and learning in a social context. Preparing appropriate environments for learners with different needs is essential to learning in general and online learning in particular. Yet, in order to create such learning environments, educators must understand differences in students' learning styles. Although some research focuses on the effects of individual differences such as age and gender on the use of social networking sites, experimental research related to students' learning styles is still limited. This study used Kolb's Learning Style Model to investigate differences in student learning outcomes and satisfaction using mobile Facebook for learning, according to learning style. Results showed that participants with "Assimilating" and "Diverging" learning styles performed better than those with "Accomodating" and "Converging" learning styles did and had higher selfefficacy, observational modelling and habit strength toward learning in mobile Facebook. The paper also makes suggestions for integrating mobile Facebook into class and recommendations for future research.
\end{abstract}

Keywords: Facebook; learning styles; social networking sites 


\section{Introduction}

Online social networking is widespread in today's society. In educational contexts, social networking sites have been used to establish relationships with peers, provide social support, create information, and maintain contact (Yu et al., 2010). Hwang et al. (2004) demonstrated that college students' social networking with professors and peers boosts their knowledge acquisition and improves their academic performance. Mobile Facebook has been investigated to be a better learning environment in higher education than other commonly used learning management systems in facilitating interaction, communication, collaboration, and learning motivation (Chen, 2014). Mobile Facebook provides a learning environment more suitable than other learning management systems that educators are already familiar with especially in facilitating opportunities for interaction, dissemination learner-created content, student engagement, and immediateness (Gabarre et al., 2013). However, research has shown that online social networking does not benefit all aspects of learning (Friesen \& Lowe, 2012). Social interaction is limited when learning in social networking sites unless required, students need support to navigate learning contents, and need personal strategies to manage online presence and participation (Veletsianos \& Navarrete, 2012). Learning style discusses learners' personal differences in preferences to receive and process information during instruction (Aragon, J ohnson, \& Shaik, 2002). It influences students' motivation and technology use (Özgen \& Bindak, 2012). Individual learning styles should be considered by teachers and other education practitioners when designing and implementing classroom activities utilizing social networking sites. Preparing a learning environment that reflects students' needs is essential in improving their academic performance (García et al., 2008).

Kolb's Learning Style Model is based on the insights of his Experiential Learning Theory (Kolb, 1984). Kolb (p. 41) defines learning as "the process whereby knowledge is created through the transformation of experience. Knowledge results from the combination of grasping and transforming experience." Each individual has his or her own preferred way of organizing and retaining information (Chou \&Wang, 2000; Griggs, 1991; Hsu, 1999; Leutner \& Plass, 1998), and the educational environment should be prepared according to participants' learning preferences. Creating an appropriate environment is possible only when instructional designers and instructors understand how to do so and take effective measures to shape the environment as needed (Kaya et al., 2009).

Mobile Facebook, a commonly used online social networking site, was utilized as a learning management system in the present study to investigate the relationship between online social networking and learning styles. Participants' attitudes toward mobile Facebook based on social cognitive theory are also discussed.

This work is licensed under a Creative Commons Attribution 4.0 International License. 


\section{Theoretical Foundation}

Web 2.0 (see O'Reilly, 2005) is considered to constitute a cooperative learning environment. The term was popularized by Dale Dougherty of O'Reilly Media and Craig Cline from MediaLive when it was used in the name for the first Web 2.0 Conference in San Francisco 2004. As one aspect of Web 2.0, online social networking sites have become a popular part of daily life. People have become inclined to develop social relationships with friends, classmates, colleagues, and family members by using social networking sites such as Facebook, Twitter, and Tumblr. Online social networking is now deeply embedded in young people's lifestyles, as evidenced by the fact that university students are the majority of social networking site users (Madge et al., 2009; Subrahmanyam et al., 2008). From an educational point of view, social networking sites are quite suitable for integration into the university setting because the learning environment of the university itself is a social system in which students interact with others in an academic context (Hwang et al., 2004). Online social networking fosters self-initiated learning by allowing students to develop personal links amongst themselves. For instance, online social networking sites enable interaction, collaboration, resource sharing, active participation, and critical thinking in educational activities (Ajjan \& Hartshorne, 2008; Irwin et al., 2011; Mason, 2006; Sánchez et al., 2014). Moreover, research shows that undergraduates with a certain level of self-regulation improve their academic performance by interacting with their peers in web-based learning activities (Wang \& Wu, 2008). Online educational activities delivered through social networking services can also be a good idea because this approach takes advantage of the fact that most students already spend a lot of time on such websites.

Most prior studies in this area have investigated personal online social networks as they relate to better academic and job performance, and other elements commonly recognized as aspects of professional and life success (Podolny \& Baron, 1997; Seibert et al., 2001; Yu et al., 2010). Moreover, with the rapid growth of mobile learning, researchers have shifted their attention to combining mobile learning with social networking sites in the education context (Pimmer et al., 2012; Rambe, 2013). Mobile Facebook could be a convenient way for students to exchange learning resources and learn ubiquitously (Gabarre et al., 2013; Pimmer et al., 2012). However, little attention has been paid to how educators can provide an adaptive mobile learning environment utilizing social networking sites that takes learning styles into consideration (GarcíaMartín \& García-Sánchez, 2013; Lin et al., 2013). Moreover, some students regarded Facebook as a platform only for socialization (Madge et al., 2009), and would rather learn in a face-to-face course (Baran, 2010), and some scholars cautioned against its use for educational purpose (Selwyn, 2009). In this sense, educators should plan more carefully when utilizing Facebook to meet individual needs in the education domain.

In this study, mobile Facebook was nevertheless selected as the social networking site to be investigated because even though it is the most popular such site, with 1.32 billion monthly active users and 1.07 billion monthly active users using Facebook mobile products (Facebook, 2014), relevant experimental research determining the educational value remains limited (Manca \& 
Ranieri, 2013). The penetration rate of Facebook in Taiwan, at 65\%, is the highest in the world, with 15 million active users per month in the last quarter in 2013 (The China Post, 2014). Facebook is described as "giving people the power to share and make the world more open and connected" (Facebook, 2014). Research shows that Facebook has sharply increased its influence on university students in recent years (Duncan \& Barczyk, 2013; Teo, 2014).

Preparing appropriate environments for learners with different needs is essential if they are to navigate the academic process successfully. However, the creation of such learning environments is not possible without first understanding differences in students' learning styles (Popescu, 2010; Wang et al., 2006). Researchers hold different perceptions of learning styles; among them, one of the most commonly used models is that proposed by Kolb (1984). Kolb created a "Learning Style Model" to explain the concept of learning styles, recognizing four learning stages, as shown in Figure 1. These stages are as follows: Concrete Experience (CE), Reflective Observation (RO), Abstract Conceptualization (AC) and Active Experimentation (AE). The stages are associated with four different learning styles. For example, a student with the converging learning style favors the learning stages of abstract conceptualization and active experimentation.

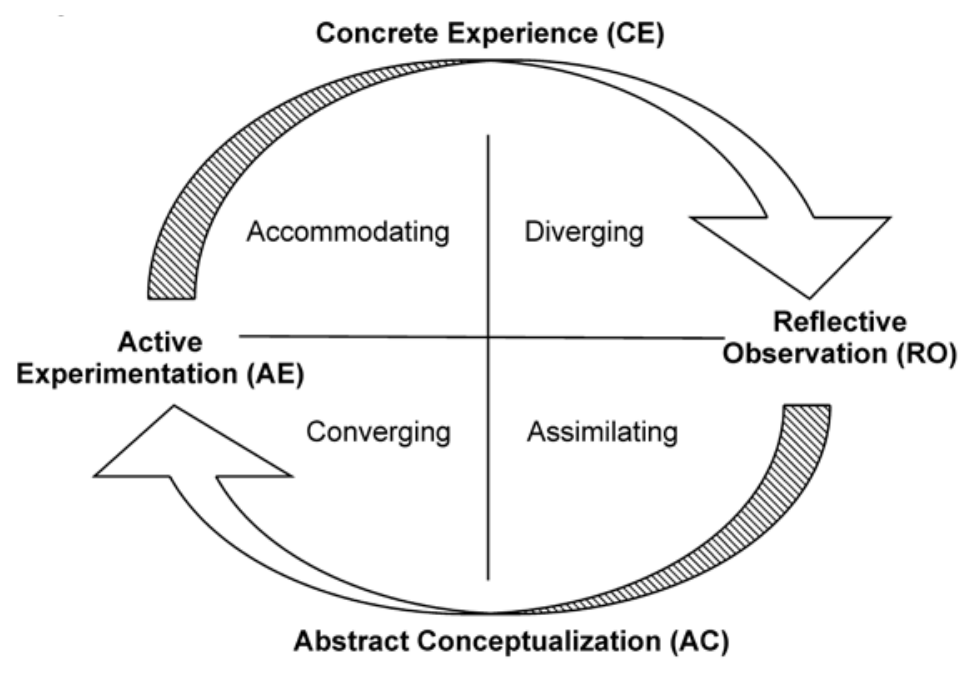

Figure 1. Four learning stages and learning styles (revised from Kolb 1999, p. 4).

1. Converging Learning Style: People with this learning style learn best with abstract conceptualization and active experimentation. They excel in decision-making, problem-solving, logically analyzing ideas, and systematic planning. When faced with a specific problem, they use hypothetico-deductive reasoning (e.g., Smith \& Kolb, 1996). They prefer creating new ideas and simulations to other problem-solving approaches (Kolb \& Kolb, 2005).

This work is licensed under a Creative Commons Attribution 4.0 International License. 
2. Diverging Learning Style: People with this learning style make use of concrete experience and reflective observation. They are characterized by their thinking ability, and they often emphasize values and concepts. They tend to synthesize various observations to generate new ideas (Hsu, 1999). They take their thoughts and feelings into consideration when forming their ideas.

3. Assimilating Learning Style: People with this learning style favor abstract conceptualization and reflective observation. They are good at creating conceptual models. They focus on abstract concepts and observing before taking action in learning. In place of actions, these learners prefer reading and exploring analytical models (Kolb \& Kolb, 2005).

4. Accommodating Learning Style: People with this learning style learn by doing and feeling. They like making and carrying out plans and designing new experiments (Kolb \& Kolb, 2005). They adapt easily to new environments and they are openminded when learning new things.

Different learning environments influenced students with different learning styles. Wang, Wang, Wang, and Huang (2006) developed a BioCAL web-based system in a nature science and life technology course. The system provided multimedia and animations for junior high school students to perceive information. Students with Diverging learning style performed best. Sun, Lin, and Yu (2008) tried to explore the learning effect in a web-based virtual science laboratory for fifth graders. The Accommodating students made the most significant achievement because they benefited from the concrete experience gained from the virtual lab environment. Özgen and Bindak (2012) examined opinions among high school students and concluded that diverging and accommodating students, who benefited most from concrete experiences, had more positive attitude towards using computers in mathematics education. Çakıroğlu (2014) developed an online computer program for sophomore students. The Diverging students demonstrated higher average scores from watching computer programming examples and learned from observation.

Social cognitive theory is usually used to investigate users' behaviour in social networking sites (Khang, Han, \& Ki, 2014; Lee, Kim, \& Kim, 2012; Lee \& Ma, 2012; Mbati, 2013). The theory provides a theoretical framework to describe and predict human behaviours (Bandura, 1986) as well as trying to investigate the relationships among personal, behavioural, and environmental influences (Bandura, 1986, 1997). According to the social cognitive theory, habit strength and self-efficacy are factors that affect individual behaviour (Khang et al., 2014). Habit strength represents an individual's pattern of behaviour (LaRose \& Eastin, 2004) and it is believed to influence his/ her current behaviour. Therefore it is expected to be a vital factor that leads to social media use. Self-efficacy has been identified as one of the determinants of individual motivation and behaviour (Bandura, 1989, 1995; Wang \& Wu, 2008; Zimmerman, 2000). Self-efficacy is defined as the belief "in one's capabilities to organize and execute the courses of action required to produce given attainments" (Bandura, 1997, pp. 3). It refers to one's confidence in his/ her

This work is licensed under a Creative Commons Attribution 4.0 International License. 
abilities to succeed in certain activities to achieve one's goals (Bandura, 1997) and it has been a significant predictor of students' achievement (Bandura, 1997; LaRose, Mastro, \& Eastin, 2001). Research papers also show that self-efficacy has positively influenced achievement in online courses (Pan et al., 2005; Wang \& Wu, 2008). According to Bandura (1986), observational modelling is at the heart of the diffusion process. Unlike blind mimicry or imitation, modelling is a more complex process through observing behaviours, interpreting the behaviours and extract key elements, and then adjusting their own behaviours (Stefanone, Lackaff, \& Rosen, 2010). Modelling could occur through nonverbal communication and verbally exchange information with others. Through modelling, learners could skip the trial and error process and learn from their observed models (Baronowski, Perry, \& Parcel, 1997). Yi and Davis (2003) further explained that observational modelling contributes to better performance in training.

In view of the previous literature on the benefits of using online social networking sites in the educational context, this study implemented activities using mobile Facebook in a university class setting in Taiwan to 1) examine whether mobile Facebook would be beneficial to groups of students with different identified learning styles in online learning, 2) document students' attitudes towards using mobile Facebook for educational purposes based on the social cognitive theory, and 3) investigate students' experiences using mobile Facebook in online learning.

\section{Methodology}

\section{Participants and Procedure}

A quasi-experimental research model was used in this study. The research was conducted in an Electronic Commerce class in a university in Taiwan; 134 students participated. The average age of the participants was 21.66; of these, 57 , or $51.43 \%$, were male and 54 , or $48.57 \%$ were female. The participants signed the informed consent forms. The institution where the study was conducted did not require such approval and the consent forms were the initiative of the author. All students were required to read course materials and participate in discussion activities on a weekly basis as part of the course curriculum. Besides uploading their own posts, students were asked to reply to at least one of their peers' posts. At least 230 posts were produced in each discussion. The entire treatment lasted for nine weeks. The students were invited to use their mobile devices to participate in the Facebook group developed for the class. To ensure that every student had access to the mobile technology to use the Facebook app, an ASUS 7" tablet PC was made available for campus and home use during the treatment if the student didn't have any mobile device of his or her own. The instructor uploaded course materials in videos, graphs, and documents. The content included abstract concepts and practical cases. The class activities included weekly discussions and problem solving assignments such as marketing students' graduation projects using social networking sites. The discussion questions via Facebook "Events" were set up, with around 22 to 24 students in a group, each week. That is, six Facebook events

This work is licensed under a Creative Commons Attribution 4.0 International License. 
with same discussion questions were created to make discussions more manageable. Since screen size is one impediment to the use of mobile Facebook (Gabarre et al., 2013), all uploaded materials were modified to be mobile friendly, for instance by using bullet points and reorganizing text into small chunks. The quantitative data collected consisted of pre- and posttest scores and responses from a "Facebook Use Questionnaire" after the treatment, while the qualitative data were collected from interviews after the treatment. The participants were also asked to take a "Learning Style Questionnaire" as part of the pretest.

\section{Quantitative Tools}

The participants were required to take a pretest before the treatment and a comprehensive quiz after the treatment to help investigate whether there is any significant difference in learning outcomes among different learning styles. Each of the pretest and the comprehensive quiz included 14 questions examining students' knowledge, application, and analysis abilities that were highly related to the course content. The quiz was developed by the instructor and reviewed by two content experts.

The Learning Style (LS) Questionnaire was conducted at the beginning of the study to explore participants' learning styles. This questionnaire was adapted from Kolb's Learning Style Inventory (Kolb 1999; Smith \& Kolb 1996), and includes 12 questions each consisting of four descriptions. From the questionnaire, Concrete Experience (CE), Reflective Observation (RO), Abstract Conceptualization (AC), and Active Experimentation (AE) scores for each participant were determined. After subtracting each student's RO score from his or her AE score and subtracting his or her CE score from his or her AC score, each participant's learning style was classified as Accommodating, Assimilating, Converging, or Diverging.

The Facebook Use Questionnaire investigating students' attitudes based on social cognitive theory towards using Facebook in the class was administered at the end of the study. The questionnaire included 13 questions on a five-point Likert-type scale, running from 1 (="Strongly Disagree") to 5 ("Strongly Agree"). The questions included (a) three questions about students' self-efficacy of learning achievement using mobile Facebook, such as: "I believe I could succeed in this mobile Facebook integrated class, " (b) six questions regarding students' attitude towards observational modelling, such as: "I learned from others' work in the Walls, " and (c) four questions related to students' habit strength of using Facebook in the course, such as: "learning in the mobile Facebook is part of my usual routine. "

To determine the validity of the questionnaire, principal component analysis was performed on the 13 questions. Three factors were yielded by means of the factor analysis. Factor one included questions 1, 2, and 9, and was named "students' self-efficacy of learning achievement through Facebook." Factor two included questions 3-8 and was named "students' attitude towards observational modelling." Factor three consisted of questions 10-13 and was called "students' habit strength of using Facebook in the course." The total variance accounted for by the three factors was $75.98 \%$. Respondent ratings for factors one to three obtained from the questionnaire

This work is licensed under a Creative Commons Attribution 4.0 International License. 
were judged to be fairly reliable, with internal consistency reliability coefficients of $0.851,0.922$, and 0.938 respectively.

\section{Qualitative Tools}

Interviews were conducted at the end of the study to assess students' feelings regarding their experience of using Facebook in the class and garner any recommendations. The interviews were conducted face-to-face on campus after the end of the nine-week treatment. Six students in each learning-style group-Accommodating, Assimilating, Converging, and Diverging - were randomly chosen. Each interviewee signed a consent form prepared by the researcher prior to the interview. The interviews were video-recorded and transcribed; each student was coded using an abbreviated code and a number: for instance, "Con 1" stands for the first student selected from the Converging group (and so on for the other groups).

\section{Results}

\section{Learning Style and Learning Performance}

To answer Research Question 1, "Is there a significant difference in test scores among students with different learning styles (Diverging, Assimilating, Converging, and Accommodating)?" an analysis of variance (ANOVA) was conducted on the pre-test and then an analysis of covariance (ANCOVA) was employed. After analyzing the pre-test scores using ANOVA, the results showed that there was no significant difference among different learning style groups $(F=14.98, p=.82)$. In assessing the homogeneity of regression, it was found that the F-test result for the product terms for each learning style and the pretest scores did not violate the regression's assumption of homogeneity $(\mathrm{F}=13, \mathrm{p}=.72)$. Therefore an interaction effect did not exist and we can safely assess the effects of learning style on achievement, controlling for the pretest score. The results of the Ftest support the existence of an effect of learning styles on participants' learning scores ( $F=14.98$, $\mathrm{p}<0.05$ ). A post hoc analysis (least significant difference method) was performed for further comparison. The results showed that the mean scores of the Assimilating group ( $M=83.76$, $\mathrm{s}=4.07)$ and the Diverging group ( $\mathrm{M}=81.87, \mathrm{~s}=5.35)$ were significantly higher than the mean scores for the Converging group ( $M=69.92, s=5.01)$ and the Accomodating group $(M=66.83$, $\mathrm{s}=6.89$ ). The results are shown in Table 1. 
Table 1

Results of Academic Performance

\begin{tabular}{llll}
\hline Groups & Pre-test & Post-test & $\mathrm{N}$ \\
\hline & Mean/ S. D. & Mean/ S. D. & \\
\hline Accomodating & $41.47 / 5.65$ & $66.83 / 6.89$ & 34 \\
Assimilating & $42.50 / 7.32$ & $83.76 / 4.07$ & 36 \\
Converging & $39.42 / 6.13$ & $69.92 / 5.01$ & 31 \\
Diverging & $40.82 / 4.73$ & $81.87 / 5.35$ & 33 \\
Total & $41.11 / 8.52$ & $75.80 / 9.07$ & 134 \\
\hline
\end{tabular}

\section{Attitudes Toward Learning in the Facebook Environment}

ANOVA was used to answer Research Question 2. "Is there a significant difference in attitudes towards learning in the mobile Facebook environment among students with different learning styles (Diverging, Assimilating, Converging, and Accommodating)?" The Facebook Use Questionnaire regarding students' attitudes towards learning after integration of mobile Facebook into the class was administered to the students at the end of the nine weeks of the treatment in order to answer this research question. As mentioned above, this questionnaire included three dimensions: (a) students' self-efficacy toward learning in mobile Facebook; (b) observational modelling through mobile Facebook; and (c) habit strength in using mobile Facebook.

\section{Students' self-efficacy toward learning in mobile Facebook.}

A composite score from questions 1, 2, and 9 was used to determine students' self-efficacy of learning in mobile Facebook. Composite scores could range between 3 and 15. There was a statistically significant difference in students' self-efficacy toward learning in Facebook among students with different learning styles (Diverging, Assimilating, Converging, and Accommodating $\left(\mathrm{F}_{3,130}=108.54, \mathrm{p}<0.01\right)$. After further analysis using Scheffés post hoc test, the students in the Assimilating group ( $M=13.56, \mathrm{~s}=1.30$ ) and the Diverging group ( $M=13.03, \mathrm{~s}=1.69$ ) scored significantly more highly than those in the Accommodating group ( $\mathrm{M}=8.88, \mathrm{~s}=1.34$ ) and the Converging group ( $\mathrm{M}=9.07, \mathrm{~s}=1.21$ ). These results are shown in Table 2. 
Table 2

Students' Self-Efficacy toward Learning in Mobile Facebook

\begin{tabular}{lllll}
\hline Learning Style & & Mean & SD & $\mathrm{n}$ \\
\hline Accommodating & 8.88 & & 1.34 & 34 \\
Assimilating & 13.56 & 1.30 & 36 \\
Converging & 9.07 & 1.21 & 31 \\
Diverging & 13.03 & 1.69 & 33 \\
Total & 11.20 & 2.58 & 134 \\
\hline
\end{tabular}

\section{Observational modelling through mobile Facebook.}

A composite score from questions 3-8 was used to determine the level of observational modelling through Facebook. Composite scores could thus range between 6 and 30. There was a statistically significant difference in students' level of observational modelling through Facebook among different learning styles (Diverging, Assimilating, Converging, and Accommodating) $\left(\mathrm{F}_{3,130}=56.96, \mathrm{p}<0.05\right)$. Results of Scheffé's post hoc test showed that students in the Assimilating group ( $M=26.11, \mathrm{~s}=2.50)$ and the Diverging group ( $\mathrm{M}=25.42, \mathrm{~s}=3.31)$ scored significantly more highly than those in the Converging $(M=19.29, s=3.13)$ and the Accomodating group $(M=17.65$, $\mathrm{s}=4.09$ ). These results are shown in Table 3 .

Table 3

Observational Modelling through Mobile Facebook

\begin{tabular}{llll}
\hline Learning Style & Mean & SD & $\mathrm{n}$ \\
\hline Accommodating & 17.65 & 4.09 & 34 \\
Assimilating & 26.11 & 2.50 & 36 \\
Converging & 19.29 & 3.13 & 31 \\
Diverging & 25.42 & 3.31 & 33 \\
Total & 22.22 & 4.96 & 134 \\
\hline
\end{tabular}

\section{Habit strength of learning in mobile Facebook.}

A composite score from questions 10-13 was used to determine the level of habit strength in learning through mobile Facebook. Composite scores could range between 4 and 20. There was a statistically significant difference across learning styles $\left(\mathrm{F}_{3,130}=16.74, \mathrm{p}<0.01\right)$. The mean scores of the Assimilating group ( $M=17.25, \mathrm{~s}=1.89)$ and the Diverging group ( $M=16.73, \mathrm{~s}=2.08)$ were 
higher than those of the Converging $(M=12.29, s=3.20)$ and the Accommodator $(M=10.35$, $\mathrm{s}=2.83$ ) group. The results are shown belowin Table 4.

Table 4

Habit Strength of Learning in Mobile Facebook

\begin{tabular}{llll}
\hline Learning Style & Mean & SD & $\mathrm{n}$ \\
\hline Accommodating & 10.35 & 2.83 & 34 \\
Assimilating & 17.25 & 1.89 & 36 \\
Converging & 12.29 & 3.20 & 31 \\
Diverging & 16.73 & 2.08 & 33 \\
Total & 14.22 & 3.72 & 134 \\
\hline
\end{tabular}

\section{Users' Experience and Attitudes Toward Mobile Facebook}

In order to answer Research Question 3, 'What are students' experiences of and attitudes toward integrating mobile Facebook in their learning?," qualitative data were collected via interviews administered to selected students at the end of the nine weeks of study. A total of 24 students-six from each learning-style group-participated in the face-to-face interviews, conducted on campus. The common themes from students' comments during the interviews are discussed below by learning style.

\section{Easy interface and convenience in mobile Facebook.}

Students across all learning styles generally expressed the opinion that mobile Facebook provided an environment in which it was simple for them to upload and edit their ideas. One student (Ass 5) mentioned that "mobile Facebook was very convenient, since I have used Facebook quite often before this class. Using mobile Facebook is part of my life. I don't need to remember another username and password or another URL." Students felt that mobile Facebook was a convenient tool, in that every participant's posts are viewable immediately. Another student (Div 23) stated that "the most interesting thing about mobile Facebook was that all my classmates' ideas can be seen immediately. Facebook sent out messages to remind me if there was any change in our discussions." Students also felt that mobile Facebook was a simple environment. In this regard, one student (Con 14) mentioned that "mobile Facebook was easy to use and the layout was clear. Finding resources such as bulletin board, class videos, and discussion page was not difficult for me."

\section{Accomodating group: Sharing practical experiences.}

Most students in the Accomodating group felt that the process of practical practices helped them to learn most and that mobile Facebook provided them with an efficient tool to share their

This work is licensed under a $\underline{\text { Creative Commons Attribution } 4.0 \text { International License. }}$ 
experiences as well as to exchange thoughts with others. One student (Acc 3) said, "I learned most from practicing how to e-market my graduation projects and the process helped me to learn what was taught in the class. Moreover, I was very willing to share my experiences and discuss with others on mobile Facebook."

\section{Assimilating: Reflecting and organizing ideas.}

Most students in the Assimilating group said mobile Facebook provided an environment for them to come to understand other students' ideas and helped them to reflect and organize ideas before they posted. One student (Ass 6) said that "reading others' messages helped me understand others' ideas more thoroughly. I could have more time to think and post when I was ready." Participants in this group needed model messages to keep them on the right track. Another student (Ass 23) remarked, 'I always read others' messages before I post. Others' messages helped me to understand the topics and requirements. A model message is even better because others' work may not be completely correct."

\section{Converging: Learned from problem solving and willingness to express ideas.}

Most participants in the Converging group mentioned that participating in case study discussions motivated them to learn. Another student (Con 20) said, "The process of trying to solve the problem in the case study was very interesting and pushed me to understand the concepts more thoroughly." In addition, most of them agreed that they felt comfortable expressing themselves in mobile Facebook. One student (Con 11) said, "I was more willing to take part in discussions in mobile Facebook than in a face-to-face class. I felt less pressure to participate on mobile Facebook."

\section{Diverging group: Learned from others and model cases.}

The discussions were available to all students, and most students in the Diverging group agreed that they learned from others' ideas. One student (Div 16) mentioned that 'I usually read others' messages before I post because I wanted to be on the right track. Reading and sharing were the best ways for me to learn." Another student (Div 31) stated, "The work we presented on mobile Facebook was open to everyone, so the positive competition forced me to improve my work. I liked to make my work better than others." Moreover, most students in this group agreed that reading exemplary real-world e-commerce cases helped them to learn.

\section{Recommendations from the participants.}

There were several recommendations provided by the participants, related both to the features of mobile Facebook itself and to the nature of the learning activity implemented in the class. First, privacy was the main concern of the participants, across all learning styles. Most of them worried that their personal information would be exposed to fellow students they didn't know very well. To address this concern, mobile Facebook should work on the safety issue and provide clear

This work is licensed under a Creative Commons Attribution 4.0 International License. 
information about related settings and changes to them. Distraction is another issue that the students worried about. The games, photos, films, and other social and recreational content on mobile Facebook certainly have the potential to distract them from learning and to waste a great deal of time. Participants also mentioned that mobile Facebook should enable users to sort their groups, since the interface can be overwhelming to navigate for people involved in too many groups on the site.

\section{Discussion}

In this study, we tried to find out how different learning styles might influence performance and attitudes in a situation where electronic commerce learning was being supported with a popular social networking tool-mobile Facebook. In our experimental class, the average learning scores of the Assimilating (83.76) group and the Diverging group (81.87) outpaced those of the Converging group (69.92) and the Accommodating group (66.83). This suggests that learning styles in the RO (Reflective Observation) dimension (that is, Assimilating and Diverging) benefited more than those in the $\mathrm{AE}$ (Active Experimentation) dimension (Accommodating and Converging). That means that the "watching" learning style showed better performance than the "doing" learning style. This result is somewhat inconsistent with prior research regarding science learning for elementary school students in a Web-based virtual science laboratory (Sun, Lin, \& Yu, 2008), which concluded that students in the Accomodating group made the most significant achievements. On the other hand, the results in the present study were partially consistent with a study conducted by Çakıroğlu (2014) that suggests that the Diverging style achieved the best average scores when learning computer programming in an online course. These differences may come from differences in utilized learning technologies because learning styles benefits from various online learning technologies and strategies (Çakıroğlu, 2014). The Web-based virtual science laboratory conducted by Sun et al. (2008) provides students with an environment to experiment and gain hands-on experiences that benefits Accomodators. Besides, the online learning system in Çakıroğlu's study (2014) provides an environment conducive to effective perception of concrete experiments (that is, computer language programming) that improve Divergers' learning, in contrast to discussion forums in online social media, which foster observational modelling (Mbati, 2013) of abstract conceptualization and real-life cases regarding electronic commerce in mobile Facebook in the present study .

With regard to the "Facebook Use Questionnaire" results, participants in the Diverging and Assimilating groups felt more satisfied with observational modeling, self-efficacy, and habit strength toward mobile Facebook than did students in the Accomodating and Converging groups. These findings are consistent with the results of the interviews. Participants in the Diverging and the Assimilating groups remarked that mobile Facebook provides an environment in which they can benefit from observing real electronic commerce cases and other students' contributions. Observational modelling facilitates higher self-efficacy beliefs in learning (Law \& Hall, 2009) and

This work is licensed under a Creative Commons Attribution 4.0 International License. 
habit strength as well as self-efficacy result in individual behaviours (Khang et al., 2014). For people in the RO (Reflective Observation) dimension, mobile Facebook provides an observational modelling environment facilitating self-efficacy beliefs and habit strength in learning utilizing mobile Facebook, enhancing their academic performance and giving them higher satisfaction.

Online social networking enables easier and more effective social support, collaborative information-sharing, content creation, and knowledge aggregation (Lee \& McLoughlin 2008). In social learning which conducted from the social networking media environment, students learn from one another by observational learning (Zhou, Man, Chen, Wu, \& J in, 2014). Moreover, offering a learning environment that meets the needs of students' learning styles increases their performance (Graf et al., 2010; Liegle \& Janicki 2006; Lu et al., 2007). Participants in the Diverging group agreed that mobile Facebook provided an observational modelling environment well suited for students to learn from others' work and real-life cases posted. The Diverging students learned best from observing concrete situations from different perspectives (Manochehr, 2006). Exemplary messages need to be provided especially to participants in the Assimilating groups, to help them reflect and synthesize various observations to generate new ideas (Hsu, 1999). Further decrease their anxiety around engaging in discussion on mobile Facebook. The findings are consistent with researchers' (Arnold \& Paulus, 2010; Mbati, 2013) conclusions that online social media are ideal for stimulating observational modelling in online learning. Moreover, Facebook facilitates students who are not active to increase their participation in learning activities (Meishar-Tal, Kurtz, \& Pieterse, 2012). For students in the reflective observation dimension (Diverging and Assimilating), instructors could not only provide learning content and exemplary works, but encourage their involvement by designing micro-assignments that could be completed in a shorter time, tagging students in posts, setting up Facebook Events to invite their participation in class activities, enabling the function that allows students to follow Facebook group happenings, and clicking “Like” to others' posts on the Wall.

More concrete experiments and chances to share should be provided for students in the Accommodating groups to improve their learning. They usually learn through problem solving by trial-and-error (Demirbas \& Demirkan, 2007). Chances to solve problems should also be available for Converging groups to illustrate target knowledge. According to Smith and Kolb (1996), converging students are capable of solving problems and good in making decisions. They are also good at finding practical applications for theories (Hsu, 1999). For students in the active experimentation dimension (Accommodating and Converging), instructors should encourage students to solve the problems in the homework, share resources related to the course on the Wall, fulfill self-expression by creating multimedia content on their mobile devices and then uploading them to mobile Facebook.

From the perspective of educators, providing more course materials, such as related readings, video clips, and PowerPoint files, is also recommended to attract participants to learning in the mobile Facebook environment.

This work is licensed under a Creative Commons Attribution 4.0 International License. 
Facebook for mobile phones is a relatively new tool for instructional purposes. The unfamiliarity of this new technology may influence users' willingness to use it. Having more time and experience with the new technology, however, may improve not only willingness but also students' interactions with one another, becoming a virtuous circle. One limitation of this paper is that its focus is mainly on college students using mobile Facebook to learn electronic commerce. Similar studies could be conducted to examine the effects on different levels of learner or in different teaching strategies to link in the relationship between learning styles and the successful educational use of the online social networking tool mobile Facebook.

\section{Acknowledgements}

The author would like to thank the insightful suggestions and feedback of anonymous reviewers. 


\section{References}

Ajjan, H., \&Hartshorne, R. (2008). Investigating faculty decisions to adopt Web 2.0 technologies: Theory and empirical tests. The Internet and Higher Education, 11(2), 71- 80.

Aragon, S. R., J ohnson, S. D., \& Shaik, N. (2002). The influence of learning style preferences on student success in online versus face-to-face environments. The American J ournal of Distance Education, 16(4), 227-243.

Arnold, N. \& Paulus, T. (2010). Using a social networking site for experiential learning: Appropriating, lurking, modeling and community building. The Internet and Higher Education, 11(2), 71-80.

Bandura, A. (1986). Social foundations of thought and action: A social cognitive theory. Englewood Cliffs, NJ : Prentice Hall.

Bandura, A. (1989). Human agency in social cognitive theory. American Psychologist, 44(9), 1175-1184.

Bandura, A. (1995). Self-efficacy in changing societies. New York: Cambridge Press.

Bandura, A. (1997). Self-efficacy: The exercise of control. New York: Freeman.

Baran, B. (2010). Facebook as a formal instructional environment. British J ournal of Educational Technology, 41(6), 146-149.

Baranowski, T., Perry, C., \& Parcel, G. (1997). How individuals, environments, and health behaviour interact: Social cognitive theory. In K. Glanz, F. M. Lewis, \& B. K. Rimer (Eds.), Health behaviour and health promotion (pp. 143-178). San Francisco, CA: J ossey-Bass.

Çakıroğlu, Ü. (2014). Analyzing the effect of learning styles and study habits of distance learners on learning performances: A case of an introductory programming course. The International Review of Research in Open and Distance Learning, 15(4), 161-185.

Chen, Y. (2014). The effect of using a Facebook group as a learning management system. Computers in Education J ournal, 5(4), 42-53.

Chou, H. \& Wang, T. (2000). The influence of learning style and training method on self-efficacy and learning performance in WWW homepage design training. International J ournal of Information Management, 20(6), 455-472.

This work is licensed under a $\underline{\text { Creative Commons Attribution } 4.0 \text { International License. }}$ 
Demirbas, O. O. \& Demirkan, H. (2007). Learning styles of design students and the relationship of academic performance and gender in design education. Learning and Instruction, 17, 345-359.

Duncan, D. G. \& Barczyk, C. C. (2013). Facebook in the university classroom: Do students perceive that it enhances community of practice and sense of community? International Journal of Business and Social Science, 4(3), 1-14.

Facebook (2014). Company info. Retrieved from http:// newsroom.fb.com/company-info/

Friesen, N. \& Lowe, S. (2012). The questionable promise of social media for education: Connective learning and the commercial imperative. J ournal of Computer Assisted Learning, 28, 183- 194.

Gabarre, S., Gabarre, C., Din, R., Shah, P. M., \& Karim, A. A. (2013). Using mobile Facebook as an LMS: Exploring impeding factors. GEMA Online J ournal of Language Studies, 13(3), 99115.

García, P., Schiaffino, S. \& Amandi, A. (2008). An enhanced Bayesian model to detect students' learning styles in web-based courses. J ournal of Computer Assisted Learning, 24, 305315.

García-Martín, J . \& García-Sánchez, J . N. (2013). Patterns of Web 2.0 tool use among young Spanish people. Computers \&Education, 67, 105- 120.

Graf, S., Liu, T.-C., \& Kinshuk (2010). Analysis of learners' navigational behaviour and their learning styles in an online course. J ournal of Computer Assisted Learning, 26, 116- 131.

Griggs, S. A. (1991). Learning styles counseling. ERIC Clearinghouse on Counseling and Personnel Services, University of Michigan, Ann Arbor.

Hsu, C. H. C. (1999). Learning styles of hospitality students: Nature or nurture? Hospitality Management, 18, 17- 30.

Hwang, A., Kessler, E. H., \& Francesco, A. M. (2004). Student networking behaviour, culture, and grade performance: An empirical study and pedagogical recommendations. Academy of Management Learning and Education, 3(2), 139- 150.

Irwin, C., Ball, L., Desbrow, B., \& Leveritt, M. (2011). Students' perceptions of using Facebook as an interactive learning resource at university. Australasian J ournal of Educational Technology, 28(7), 1221- 32. 
Kaya, F., Özabacı, N., \& Tezel, Ö. (2009). Investigating primary school second grade students' learning styles according to the Kolb learning style model in terms of demographic variables. J ournal of Turkish Science Education, 6(1), 11- 25.

Khang, H., Han, E., \& Ki, E. (2014). Exploring influential social cognitive determinants of social media use. Computers in Human Behaviour, 36, 48-55.

Kolb, D. A. (1984). Experiential learning: Experience as the source of learning and development. Prentice Hall, Englewood Cliffs, NJ .

Kolb, D. A. (1999). Learning Style Inventory. Version 3. Hay/ McBer Training Resources Group, Boston.

Kolb, A. Y., \& Kolb, D. A. (2005). Learning styles and learning spaces: Enhancing experiential learning in higher education. Academy of Management Learning and Education, 4, 193212.

LaRose, R., \&Eastin, M. S. (2004). A social cognitive theory of Internet uses and gratifications: Toward a new model of media attendance. J ournal of Broadcasting and Electronic Media, 48(3), 358-377.

LaRose, R., Mastro, D., \& Eastin, M. S. (2001). Understanding Internet usage: Social cognitive approach to uses and gratifications. Social Science Computer Review, 19(4), 395-413.

Law, B. \& Hall, C. (2009). Observational learning use and self-efficacy beliefs in adult sport novices. Psychology of Sport and Exercise, 10(2), 263-270.

Lee, D., Kim, H. S., \& Kim, J . K. (2012). The role of self-construal in consumers electronic word of mouth (eWOM) in social networking sites: A social cognitive approach. Computers in Human Behaviour, 28(3), 1054-1062.

Lee, C. S. \& Ma, L. (2012). News sharing in social media: The effect of gratifications and prior experience. Computers in Human Behaviour, 28, 331-339.

Lee, M. J . W., \& McLoughlin, C. (2008). Harnessing the affordances of Web 2.0 and social software tools: Can we finally make "student-centered" learning a reality? In Papers Presented at the World Conference on Educational Multimedia, Hypermedia and Telecommunications (eds. Luca J . \&Weippl E.), pp. 3825- 3834. Association for the Advancement of Computing in Education, Chesapeake, VA.

Leutner, D., \& Plass, J . L. (1998). Measuring learning styles with questionnaires versus direct observation of preferential choice behaviour in authentic learning situations: The visualizer/ verbalizer behaviour observation scale (VV-Bos). Computers in Human Behaviour, 14, 543- 557.

This work is licensed under a $\underline{\text { Creative Commons Attribution } 4.0 \text { International License. }}$ 
Liegle, J . O., \&J anicki, T. N. (2006). The effect of learning styles on the navigation needs of webbased learners. Computers in Human Behaviour, 22, 885- 98.

Lin, P. C., Hou, H. T., Wang, S. M., \& Chang, K. E. (2013). Analyzing knowledge dimensions and cognitive process of a project-based online discussion instructional activity using Facebook in an adult and continuing education course. Computers \& Education, 60(1), 110- 121.

Lu, H., Jia, L., Gong, S., \& Clark, B. (2007). The relationship of Kolb learning styles, online learning behaviours and learning outcomes. Educational Technology \& Society, 10(4), 187- 196.

Madge, C., Meek, J ., Wellens, J ., \& Hooley, T. (2009). Facebook, social integration and informal learning at university: It is more for socialising and talking to friends about work than for actually doing work. Learning, Media and Technology, 34(2), 141- 155.

Manca, S. \& Ranieri, M. (2013). Is it a tool suitable for learning? A critical review of the literature on Facebook as a technology-enhanced learning environment. J ournal of Computer Assisted Learning, 29(6), 487-504.

Manochehr, N. N. (2006). The influence of learning styles on learners in e-learning environments: An empirical study. Cheer Virtual Edition, 18, 10-14.

Mason, R. (2006). Learning technologies for adult continuing education. Studies in Continuing Education, 28(2), 121- 3133.

Mbati, L. (2013). Online social media applications for constructivism and observational learning. The International Review of Research in Open and Distance Learning, 14(5), 166-185.

Meishar-Tal, H., Kurtz, G., \& Pieterse, E. (2012). Facebook groups as LMS: A case study. The International Review of Research in Open and Distributed Learning, 13(4), 33-48.

O’Reilly, T. (2005). What is Web 2.0? Retrieved from http:// www.oreillynet.com/pub/a/ oreilly/ tim/ news/2005/ 09/30/ what-is-web20.html

Özgen, K. \& Bindak, R. (2012). Examining student opinions on computer use based on the learning styles in mathematics education. The Turkish Online J ournal of Educational Technology, 11(1), 79-93.

Pan, C., Gunter, G., Sivo, S., \&Cornell, R. (2005). End-user acceptance of a learning management system in two hybrid large-sized introductory undergraduate courses. J ournal of Educational Technology Systems, 33(4), 355-365

This work is licensed under a Creative Commons Attribution 4.0 International License. 
Pimmer, C., Linxen, S., \& Grohbiel, U. (2012). Facebook as a learning tool? A case study on the appropriation of social network sites from mobile phones in developing countries. British J ournal of Educational Technology, 43(5), 726- 738.

Podolny, M., \& Baron, J . N. (1997). Resources and relationships: Social networks and mobility in the workplace. American Sociological Review, 62, 673- 693.

Popescu, E. (2010). Adaptation provisioning with respect to learning styles in a web-based educational system: An experimental study. J ournal of Computer Assisted Learning, 26, 243- 257.

Rambe, P. (2013). Converged social media: Identity management and engagement on Facebook Mobile and blogs. Australasian J ournal of Educational Technology, 29(3), 315- 336.

Sánchez, R. A., Cortijo, V., \&J aved, U. (2014). Students' perceptions of Facebook for academic purposes. Computers \& Education, 70, 138-149.

Seibert, S. E., Kraimer, M. L., \&Liden, R. C. (2001). A social capital theory of career success. Academy of Management J ournal, 44(2), 219- 237.

Selwyn, N. (2009). Faceworking: Exploring students' education-related use of Facebook. Learning, Media and Technology, 34, 157-174.

Smith, D. M., \& Kolb, D. A. (1996). User's guide for the Learning Style Inventory. McBer and Company, Boston.

Stefanone, M. A., Lackaff, D., \& Rosen, D. (2010). The relationship between traditional mass media and "social media": Reality television as a model for social network site behaviour. J ournal of Electronic Media, 54(3), 508-525.

Subrahmanyam, K., Reich, S. M., Waechter, N., \& Espinoza, G. (2008) Online and offline social networks: Use of social networking sites by emerging adults. J ournal of Applied Developmental Psychology, 29(6), 420-433.

Sun, K. T., Lin, Y. C., \&Yu, C. J . (2008). A study on learning effect among different learning styles in a Web-based lab of science for elementary school students. Computers \& Education, 50(4), 1411- 1422.

Teo, T. (2014). Modelling Facebook usage among university students in Thailand : The role of emotional attachment in an extended technology acceptance model. Interactive Learning Environments, DOI: 10.1080/ 10494820.2014.917110.

The China Post (2014). More Taiwanese use Facebook per capita than anywhere else in world. Retrieved

This work is licensed under a Creative Commons Attribution 4.0 International License. 
from http:// www.chinapost.com.tw/ taiwan/ business/2014/03/01/401737/MoreTaiwanese.htm

Veletsianos, G. \&Navarrete, C. C. (2012). Online social networks as formal learning environments: Learner experiences and activities. The International Review of Research in Open and Distance Learning, 13(1), 144-166.

Wang, S. L. \&Wu, P. Y. (2008). The role of feedback and self-efficacy on web-based learning: The social cognitive perspective. Computers \& Education, 51(4), 1589- 1598.

Wang, K. H., Wang, T. H., Wang, W. L., \&Huang, S. C. (2006). Learning styles and formative assessment strategy: Enhancing student achievement in web-based learning. J ournal of Computer Assisted Learning, 22, 207- 217.

Yi, M. Y., \& Davis, F. D. (2003). Developing and validating an observational learning model of computer software training and skill acquisition. Information Systems Research, 14(2), 146-169.

Yu, A. Y., Tian, S. W., Vogel, D., \&. Kwok, R. C. (2010). Can learning be virtually boosted? An investigation of online social networking impacts. Computers \& Education, 55, 1494- 1503.

Zimmerman, B. J . (2000). Self-efficacy: An essential motive to learn. Contemporary Educational Psychology, 25, 82-91.

(C) Chen

\section{Athabasca University $\mathbf{a}$}

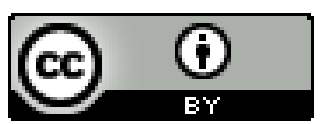

This work is licensed under a $\underline{\text { Creative Commons Attribution } 4.0 \text { International License. }}$ 